\title{
Muddiest Point Formative Feedback in Core Materials Classes with YouTube, Blackboard, Class Warm-ups and Word Clouds
}

\section{Prof. Stephen J Krause, Arizona State University}

Stephen J. Krause is a professor in the School of Materials in the Fulton School of Engineering at Arizona State University. He teaches in the areas of bridging engineering and education, capstone design, and introductory materials engineering. His research interests are evaluating conceptual knowledge, misconceptions and their repair, and conceptual change. He has co-developed a Materials Concept Inventory for assessing conceptual knowledge of students in introductory materials engineering classes. He is currently conducting research on misconceptions and development of strategies and tools to promote conceptual change in materials courses.

\section{Dr. Dale R Baker, Arizona State University}

Dr. Dale Baker is a fellow of the American Association for the Advancement of Science and the American Educational Research Association. Her research has focused on equity issues in science and engineering, teaching and learning in science and engineering and teacher professional development in science and engineering. A new area of research she is exploring is the issues surrounding increasing the number of individuals with disabilities in science and engineering and the role of adaptive technologies in increasing participation in science and engineering.

\section{Dr. Adam R Carberry, Arizona State University}

Dr. Adam R. Carberry is an Assistant Professor at Arizona State University in the College of Technology \& Innovation's Department of Engineering. He earned a B.S. in Materials Science Engineering from Alfred University, and received his M.S. and Ph.D., both from Tufts University, in Chemistry and Engineering Education respectively. Dr. Carberry was previously an employee of the Tufts' Center for Engineering Education \& Outreach and manager of the Student Teacher Outreach Mentorship Program (STOMP).

\section{Dr. Milo Koretsky, Oregon State University}

Dr. Milo Koretsky is a Professor of Chemical Engineering at Oregon State University. He currently has research activity in areas related to thin film materials processing and engineering education. $\mathrm{He}$ is interested in integrating technology into effective educational practices and in promoting the use of higher level cognitive skills in engineering problem solving. Koretsky is a six-time Intel Faculty Fellow and has won awards for his work in engineering education at the university and national levels.

\section{Mr. Bill Jay Brooks, Oregon State University}

Bill Brooks is a Ph.D. candidate in the School of Chemical, Biological, and Environmental Engineering at Oregon State University. As an undergraduate he studied hardware engineering, software engineering, and chemical engineering. Bill has been involved in the development of several educational software tools including the Virtual BioReactor, the Web-based Interactive Science and Engineering (WISE) Learning Tool, and the AIChE Concept Warehouse. His dissertation is focused on technology-mediated, active learning techniques and the mechanisms through which they impact student performance.

\section{Ms. Debra Gilbuena, Oregon State University}

Debra Gilbuena is a Ph.D. candidate in the School of Chemical, Biological, and Environmental Engineering at Oregon State University. She currently has research focused on student learning in virtual laboratories. Gilbuena has an M.B.A., an M.S., and four years of industrial experience including a position in sensor development, an area in which she holds a patent. Her dissertation is focused on the characterization and analysis of feedback in engineering education. She also has interests in the diffusion of effective educational interventions and practices. 


\section{Dr. Cindy Waters, North Carolina A\&T State University Casey Jane Ankeny, Arizona State University}

Casey J. Ankeny, Ph.D. is a postdoctoral fellow in engineering education at Arizona State University and an adjunct professor at Scottsdale Community College. Currently, she is working under Steven Krause, $\mathrm{Ph}$.D. to investigated cyber-based student engagement strategies with frequent, formative feedback in introductory courses. Casey received her bachelor's degree in Biomedical Engineering from the University of Virginia in 2006 and her doctorate degree in Biomedical Engineering from Georgia Institute of Technology and Emory University in 2012 where she studied shear- and side-dependent microRNAs in human aortic valvular endothelial cells and taught six different biology and engineering courses. She aspires to employ student engagement strategies in the context of biomedical engineering education in the future. 


\title{
Muddiest Point Formative Feedback in Core Materials Classes with YouTube, Blackboard, Class Warm-ups, and Word Clouds
}

\begin{abstract}
Critical class reflections on "Muddiest Points", i.e. the content students struggle to grasp most, provide formative feedback to an instructor who can strategize to adjust his/her teaching and pedagogy to address issues specific to a given class. In a Muddiest Point Reflection, an instructor solicits from students a brief, anonymous written comment about difficult concepts or other issues that arose during the class. It is also possible now to easily and efficiently collect and review Muddiest Point reflection responses via the web on the cyber-enabled Concept Warehouse web site http://cw.edudiv.org, which also has large sets of concept-based clicker questions (or ConcepTests) for core chemical engineering classes as well as a set of clicker questions for an introductory materials science class. The Muddiest Point method allows students to reflect on their own learning over a whole class and highlight difficulty with specific issues or concepts. Self-efficacy of students can also increase because a class can be designed so that new information is based on students' prior knowledge, in which they hopefully have confidence, and can potentially motivate them to better learn. The critical class reflections also provide a clear and easy way to track the attitudes, understanding, and learning approaches of the students in the class. Addressing learning issues as quickly as possible with rapid feedback is an important part of effective teaching and consists of first assessing and evaluating students' knowledge and understanding of a topic. Feedback directed toward learning goals which are valued by students has the potential to increase motivation and persistence in achieving the goals. The collective set of responses from a given class can be evaluated by an instructor and synthesized into feedback to be delivered to students in different ways.

In this research project on more effective teaching in core materials classes, the research question here is, "What is the effect on student learning and attitude of differing modes of feedback from students' Muddiest Point reflections?" One method is to restructure the notes from a given class and place the set on Blackboard so the new notes respond to student issues raised in Muddiest Points. This can reinforce class learning, clarify muddy points, and potentially assist in solving homework problems. A second method is with Class Warm-ups, which consist of a slide or two for discussion at the beginning of the next class which can help clarify confusing or difficult-tograsp concepts. Another method is to create Muddiest Point YouTube tutorial screencasts, such as the ones at www.youtube.com/user/MaterialsConcepts, which can be viewed by students to help resolve difficult concepts and also assist in solving homework problems. Preliminary results here show possible impact on student achievement in terms of significant gains with test results much higher than trend lines for upper, median and lower quartiles (over seven semesters) on content for which a Muddiest Point YouTube Tutorial screencast had been created. A final supplemental approach is to incorporate Word Clouds in any of the feedback methods. This allows students to visually assess and share what their most significant issues may be, with the Muddiest Point frequency of a given word from an issue revealed by the size of its word in the Word Cloud. Results show continuous improvement for positive gains on student attitude, achievement and retention.
\end{abstract}




\section{Introduction}

Class reflection points are not frequently used in engineering courses. Documenting reflective thoughts are often recorded in diaries or journals for more liberal arts and science courses. The reflections are normally about a specific topic and are simply assignments. However, these critical class reflection points are designed to provide formative feedback for the instructor allowing adjustments in teaching and pedagogy to be made specifically for a class. Using critical class reflection points will also help students to understand their role as individuals and collaborators in an engagement classroom to create a more positive learning attitude and increase retention of students. Self-efficacy of students will increase because the class is designed so that the new information is being based on their prior knowledge which they should already feel confident with and motivate them to learn. The critical class reflections provide a clear easy way to track the attitudes, understanding, and learning methods of the students in the class.

In this work we are addressing the research question, "What is the impact of class reflections, especially Muddiest Points, on student learning, attitude, and retention?" End-of-class reflection sheets have questions on "What is the Most Interesting Point?" and "What is the Muddiest Point?" It reveals what they find confusing, as well as what they find most interesting, and it is possible to discover any misconceptions or concepts that students are having difficulty with. It is then possible to address and hopefully correct the difficulties in different ways to be described. This will help the students feel more confident about a given topic and allow them to move on to the next topic with a more positive attitude. When students are asked about what they find interesting they are more likely to remember the parts of the topic that they enjoyed and an instructor will be able to better relate to them and identify what the students find fascinating. By having the students reflect on what information they found most valuable, they are determining what information will be beneficial for them to know in the future, as well as motivate them to think about the topic more in depth.

\section{Background}

\section{Motivation and Value in Learning}

Motivation is an important factor supporting students' learning. Student's choices, persistence, and effort to learning contexts independently and in groups are affected by their motivational and affective beliefs ${ }^{1}$. Previous studies have shown that two points govern student motivation: 1) the degree to which students believe they can complete a task (self-efficacy) and 2) the value the students place on the learning task ${ }^{2}$. More specifically, college students must also perceive added benefit their personal futures ${ }^{3,5}$. The degree to which students' competency beliefs and the values of the specific subject predict the quality of their learning and the amount of effort they will invest in learning the subject ${ }^{6,7}$. For example, students perceiving short term value of the material will engage in quick learning strategies, instead of mastery. An increase in social interaction would foster idea brainstorming and information gathering that could result in deeper thinking about the material. ${ }^{9}$ 


\section{Self Efficacy}

The self-efficacy is an impressive measure of human behavior as it offers both "cognitive and motivational drive" $"$. One factor that affects self-efficacy is gender. Lack of self-efficacy then in turn results in problems with technical problem solving ${ }^{11}$. In line with this notion, women possess less self-efficacy than men which leads to lower self-assessment of their problem solving skills and competence as future engineers ${ }^{12}$. The self efficacy of female students is related to the retention as freshmen and their persistence in engineering ${ }^{13,14}$. When entering into engineering, female students have less confidence in their ability to succeed in engineering ${ }^{15}$. Research has shown that the level of self-efficacy affects career choice as it pertains to science education ${ }^{16,17}$.

\section{Reflections}

Extended reflection facilitates the creation of complex, connected mental schema.Designing creative learning experiences helps develop improved reflective skills ${ }^{18}$. These reflections are also more powerful when they are written down than when they are reported orally ${ }^{19}$. Reflections can be characterized in four different frameworks: descriptive writing but not reflective, descriptive reflection, dialogic reflection, and critical reflection ${ }^{20}$. Descriptive writing reports occurences $^{20}$; whereas, descriptive reflections provide reasons for these occurrences using personal discretion ${ }^{20}$. Further, dialogical reflection extends descriptive reflections to create a dialog regarding one's self using the possible reasons for the occurrences ${ }^{20}$. Moreover, there are three levels of reflection: reacting, elaborating, and contemplating ${ }^{21}$. Reacting is when the student comments on their feelings towards their learning experience in the class ${ }^{21}$. Elaborating is when the student is comparing their reactions with other prior knowledge ${ }^{21}$. Contemplating is when the student is metacognitive about how they are learning or the difficulties they are having when they are learning ${ }^{21}$. It is important to have a written response for a given reflection since it forces a student to articulate more clearly their thoughts and feeling on a particular point on which they are reflecting ${ }^{19}$.

Hatton \& Smith found that when two or more people engage in conversation with questioning or debating helps the reflective process by allowing self-reflection to take place in a safe environment ${ }^{20}$. According to research, it is imperative that environments that promote "interpersonal interaction" so as to result in greater reflection. ${ }^{9}$ Different sources of motivation, such as internal and external, affect the reflection quality and create a challenge in terms of assessment. Internal motivation is hard to improve as well as measure. External strategies, such as creating a mental challenge, working in small groups, and fostering competition enhances motivation, but these tactics have not been validated. Anecdotally, when there is confidence in the professionalism and reviewer integrity, the amount and quality of responses are improved. This type of a reflection can be helpful for analyzing what the student did or did not find helpful in the instruction. The ability for the student to reflect on a specific topic is directly proportional to how much they already know about the subject.

\section{Class Screencasts and YouTube Tutorial Screencasts}

The breadth and amount of technology in higher education is growing rapidly. In a recent article the benefits and issues in use of lecture screencasts was reviewed in general and research on 
impact of screencasts was reported ${ }^{20}$. The study at the University of Michigan examined lecture screencast usage across many departments for many courses and found that their use was generally beneficial for students that chose to use the screencasts. This is in agreement with an earlier article on the impact of class lecture webcasting on attendance and learning ${ }^{21}$. The Falconer engineering education research group at the University of Colorado Boulder began creating screencast videos for all core chemical engineering classes in May 2010. Usage of the videos has grown dramatically, especially when they were placed on YouTube and there were over 50,000 viewings of the videos in 2011. In this research the nature of the screencast videos differs somewhat from those used at Michigan and Colorado. At Michigan, lecture screencasts use writing on normally used PowerPoint slide sets. The Colorado screencasts are shorter, usually 10 minutes or less, and generally use blank or hand-drawn templates from which additional narration is carried out while information is written on the sheet in view. In both cases faculty or faculty associates carry out instruction on the screencasts. In this work the nature of the screencasts differs somewhat from the other two approaches. In particular, our screencasts have been created to address student' Muddiest Point issues from a given class. Further details of how the screencasts are prepared are described later.

\section{Methods}

The introductory course in which the sample was drawn was a 15-week semester course required for mechanical, industrial and materials engineering majors met for seventy-five minutes two times per week. The course was taught by a professor with a Ph.D. in engineering and 30 years teaching experience. Throughout instruction students were asked to frequently express their mental models in multiple modes. Student expressions and explanations of thinking took place in different ways, or representations, including written, verbal, diagrammatical, mathematical, graphical and, kinesthetic. Following each class period students were asked to fill in the Reflection Points sheets.

\section{Reflection Point Data Collection and Recording}

At the conclusion of every class, students were asked to fill out a Reflection Points sheet. The Point of Interest allowed students to think about and convey parts of content that they find interesting and intriguing. They began to recognize topics that interested them which promoted future appreciation of knowledge. The instructor identified with the learner and see what information sparked interests in the students' thoughts. The response to the Muddiest Point forced students to identify content topics which they had trouble understanding. By asking students to reflect on their difficulties in understanding, they learned to identify conceptual weaknesses. Frequent thought of these weaknesses enabled students to be proactive in their learning in the future. The instructor was able to catch conceptual gaps as they occurred and reduced the probability for students to develop robust misconceptions. Each class reflection was cataloged for each student throughout the semester and recorded in Excel spreadsheets using the student's own anonymous class ID number. This resulted in a semester long progression of each student's thinking about each of the reflection points. 


\section{Muddiest Point YouTube Tutorial Screencasts}

The creation of screencasts in this work differs somewhat from other approaches used in engineering education that were described earlier. This approach for screencasts is based on a given class topic's Muddiest Points. For a given topic the actual student comment is used as a quote for the Muddiest Point to ensure authenticity of the language and meaning of a given student. Typically there are 25 to 35 quotes for a given class out of the 30 to 40 students that normally attend any given class. Another aspect of the Muddiest Point response is the Likert scale of 1 to 5 that allows a student to identify the "muddiness" or difficulty of the concept that is being described. Thus, the frequency and the intensity of comments are used to select the most critical issues that students have identified. Since Muddiest Points have been collected from classes over the past six semesters, sometimes earlier semester Muddiest Points for a given topic are consulted and, if issues are similar, are sometimes used.

The next step is to design a limited set of slides from the class, typically six to eight that will most effectively frame the Muddiest Points. They are usually modified to produce the most clarity and ease of flow of knowledge. The time of a given screencast varies from 10 to 20 minutes, which seems to not extend beyond the attention span of most viewers. This is in between the screencast times of 60 to 70 minutes for whole lecture screencasts, as found at Michigan, and the shorter 10 minute or less screencasts found at Boulder.

Another major difference of these screencasts is that the structure and content of the video is created by a former student in the introductory materials class. Once the student selects and modifies the desired slide set there is considerable discussion and dialogue on a given topic's slide set between the course instructor and the student. After shaping the content and concepts to be discussed, the student scripts the narration she will use during the screencast. This is reviewed with the instructor and then a screencast is made.

The screencast is produced in the Camtasia production program which is available for both Macintosh and PC platforms. However, in order to facilitate simple and easy modification of the screencast the production is created so each slide can be modified by itself and many "layers" may be used in Adobe Photoshop or Photoshop Elements for a given slide. This is so that if a minor modification is required in the slide, the entire slide does not have to be entirely redone. Once a screencast is created, there may be one or two iterations carried out to produce the simplest and clearest screencast. After that the screencast is loaded up to YouTube and titled, categorized, and a description written.

\section{Results and Discussion}

In order to illustrate the process of collecting, recording, evaluating and selecting the Muddiest Points for next-class commentary and the Muddiest Point YouTube video, an example of that process will be given based on the relatively difficult concept of indexing crystal planes in unit cell with Miller indices. The first step is to collect the Reflection Point sheets and enter the data into an Excel spreadsheet. This is shown below in Table 1 with student's original comments as written. A single Excel file is used for the whole semester by just introducing new tabs for each class which allows the student personal ID number to remain as a vertical index. Notice the 
Likert scale values to the right of each data column. The Likert average for Points of Interest was 3.43 which means students found content moderately interesting. The Likert average for Muddiest Points was 2.8 which means students found the content somewhat, but not greatly difficult. Also, what was one person's Interesting Point was another's Muddiest Point.

Table 1. Spreadsheet with Miller Indices Data for Points of Interest and Muddiest Points.

\begin{tabular}{|c|c|c|c|c|c|}
\hline \multicolumn{4}{|c|}{250 F12 Reflection 9-11 } & & \multirow[b]{3}{*}{ Muddiest Point } \\
\hline Title & \multicolumn{3}{|c|}{ Structure of Crystalline Solids: Unit Cells III } & & \\
\hline ID & & & \begin{tabular}{|c|} 
Point of Interest \\
\end{tabular} & & \\
\hline A5892 & $\mathrm{M}$ & & & 3 & Millers Indices and finding intercepts \\
\hline B1998 & $\mathrm{M}$ & 3 & Describing planes as indices & & Going from a set of indices to a 3-D depiction of \\
\hline B2448 & $\mathrm{M}$ & 1 & We should move a lot faster & 1 & Not confusing \\
\hline B5565 & $\mathrm{M}$ & 1 & Repositioning origin & 1 & Triangular Indices \\
\hline $\mathrm{C} 0504$ & $\mathrm{~F}$ & 3 & I think how crystal planes affect us are kind of interesting & 3 & Pretty much like last week, not confuse like last week \\
\hline C1199 & $\mathrm{M}$ & & & & \\
\hline $\mathrm{C} 2426$ & $\mathrm{M}$ & & & & \\
\hline C9239 & $\mathrm{M}$ & 3 & How to make planes by indexing & 5 & $\begin{array}{l}\text { Where do you make the origin and is there } \\
\text { multiple ways to solve a problem? }\end{array}$ \\
\hline D1990 & $\mathrm{F}$ & 4 & How to form planes given indices and vice versa & 3 & $\begin{array}{l}\text { The families of planes, just coming up with } \\
\text { negative numbers. I find it hard to see. }\end{array}$ \\
\hline $\mathrm{D} 2505$ & $\mathrm{~F}$ & 4 & The planes where polymers bend & & None \\
\hline E2964 & $\mathrm{M}$ & 4 & How crystal direction relates to properties & 4 & How many atoms in (111) planes \\
\hline F5053 & $\mathrm{M}$ & 5 & & 2 & Still confused on finding the amount of atoms \\
\hline G1111 & $\mathrm{M}$ & 1 & Atomic crystal structure & 3 & The triangle one \\
\hline G2139 & $\mathrm{M}$ & 4 & How to interpret directions & 4 & How to draw directions \\
\hline G2139 & $\mathrm{M}$ & & & & \\
\hline G5792 & $M$ & 5 & How different indices could draw identical planes & 2 & of $\mathrm{FCC} / \mathrm{BCC}$ \\
\hline G9748 & $\mathrm{M}$ & 2 & That there are some that go to $\infty$ and some that & 1 & Not anything today \\
\hline $\mathrm{H} 5671$ & $\mathrm{M}$ & 3 & Drawing planes & 1 & Triangular orientations \\
\hline $\mathrm{J} 1012$ & $\mathrm{M}$ & 4 & Learning how to draw planes & 2 & How to determine what unit cell planes look like \\
\hline J1031 & $\mathrm{F}$ & 3 & How crystal structure affect ductility & & $\begin{array}{l}\text { Why certain structures are more ductile i.e. why } \\
\text { is closed packed direction most malleable? }\end{array}$ \\
\hline $\mathrm{J} 1460$ & $\mathrm{M}$ & 4 & Drawing planes & 3 & Cubic structure: Activity 7 \\
\hline J5008 & $\mathrm{M}$ & 2 & & 3 & Planes families \\
\hline K1234 & $\mathrm{M}$ & 4 & White[illegible] & 4 & Drawing the planes from indices still confused \\
\hline K1421 & $\mathrm{M}$ & 4 & Structure of polymers & 2 & Families of planes \\
\hline K1974 & $\mathrm{F}$ & 5 & Drawing and indexing planes & 3 & Unit cell information II (chart from previous \\
\hline K2626 & $\mathrm{M}$ & & & & \\
\hline L5360 & & & & & \\
\hline M0626 & $\mathrm{M}$ & 4 & The bar on top (1I1) representing the negative & 3 & The triangle harder than the square or \\
\hline M1106 & $\mathrm{F}$ & & & & \\
\hline M1993 & $\mathrm{F}$ & & & & \\
\hline M3319 & $\mathrm{F}$ & 5 & Pointing out the mistake was extremely easy to do & 3 & Redrawing the planes in the unit cell. Can still be \\
\hline M4198 & $\mathrm{M}$ & 4 & How things break across planes & 3 & Families of planes \\
\hline M8987 & M & 3 & $\begin{array}{l}\text { Direction of crystal growth kind of dictates the } \\
\text { properties of a material }\end{array}$ & & None \\
\hline MW1127 & $\mathrm{M}$ & & & & \\
\hline N1396 & $\mathrm{F}$ & 3 & Indices of planes & 3 & family planes \\
\hline O3207 & $\mathrm{M}$ & 4 & Using pictures make it easier to understand planes & 2 & Still have trouble picking the different types of UC \\
\hline P5826 & $\mathrm{F}$ & & & & \\
\hline P6323 & $\mathrm{M}$ & 4 & Materials deform along the close packing plane & 4 & Visualizing the atoms along different planes ( \\
\hline $\mathrm{X} 1337$ & $\mathrm{M}$ & 4 & Planes & 4 & families of planes \\
\hline Y7062 & $\mathrm{M}$ & 3 & Drawing millers indices & 3 & Unit cell planes; center of atoms. \\
\hline
\end{tabular}


The data evaluated from the spreadsheet in Figure 1 indicated likely Points of Interest and likely Muddiest Points which is shown below in the next class commentary slide. The students like to find out what other students regard as interesting points. They also appreciate knowing what other students are having difficulty in grasping concepts. Comments are made at the beginning of class and an example or two is done. This is an ideal time to link the previous class to the slide and the student's homework problem solving in order to achieve more effective learning.

Another instructor will take the same content from his spreadsheet and create a brief explanatory video or example problem solution and post those results on Blackboard before the end of the day of the lecture so that students can access the Muddiest Point content in order to solve their homework problems.

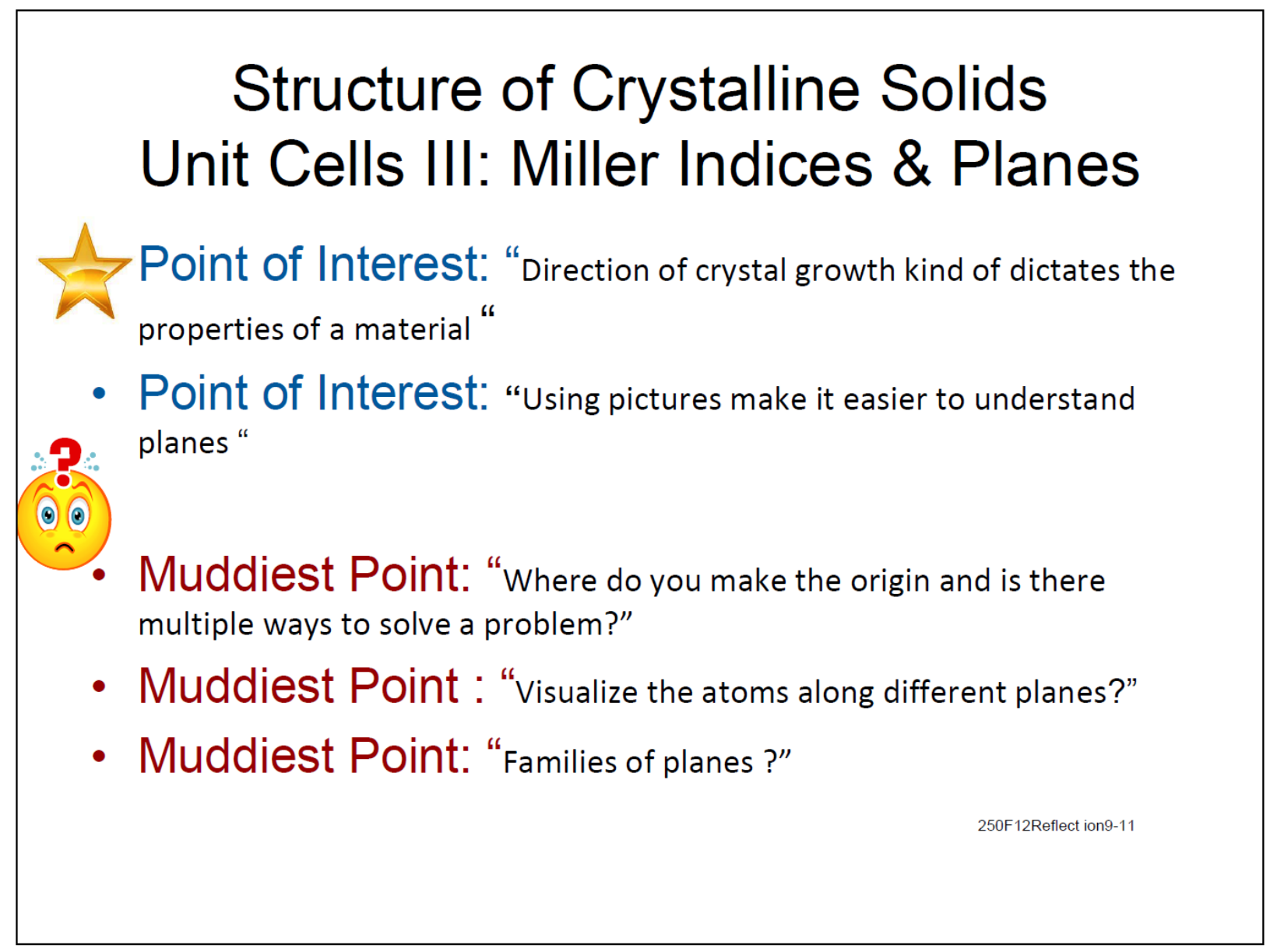

Figure 1. Next Class Reflection Points Commentary for Topic of Crystal Plane Miller Indices.

For the Muddiest Point YouTube Tutorial Video screencast the Muddiest Points from this set and also the previous four sets of Muddiest Point for this topic were used to generate the introductory slide for the YouTube video as shown in Figure 2. As can be seen, the YouTube Muddiest Points clearly reflect the difficult concepts articulated by the students in their Muddiest Point responses, although there are a few additional Muddiest Points from other semesters. These include the bracket types and the importance of crystallographic planes. These are focal points of the 
Muddiest Points video. They are also used by the instructor in future semesters to adjust instruction and make certain that these Muddiest Points are addressed in the next semester's class on the topic of crystal plane Miller indices.

\section{Muddiest Points \\ Crystal Structure III: Miller Indices of Planes in Unit Cells}

\section{Muddiest Points:}

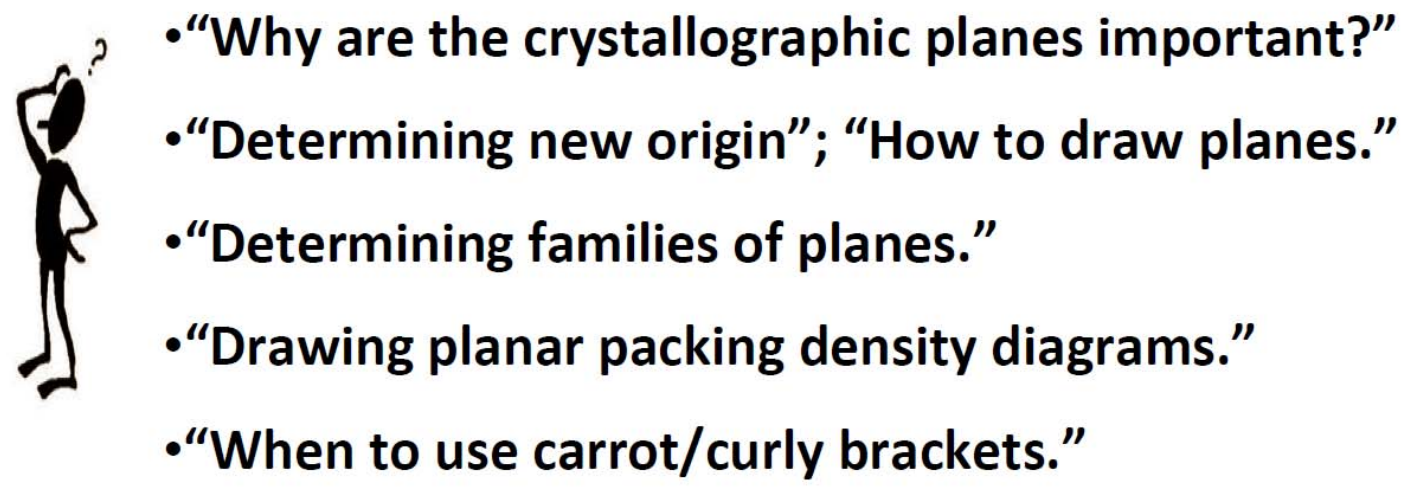

Figure 2. Muddiest Points for Miller Indices for Planes in Unit Cells

In Figure 3 is shown the first slide of the Muddiest Point YouTube Tutorial video for the topic of Miller indices for crystal planes in unit cells. This is a Print Selected Screen Area shot from an iMac computer screen. While the slide appears similar to the precious image in figure 2 , there are also some gray bars on the lower half of the slide that are called "annotations" that allow the viewer to jump to any topic listed in those bars within the YouTube video directly without having to go though any other slides. This "annotation" feature also allows the YouTube author to create a jump to any position in any other YouTube video. Thus, this feature could be quite useful for multi-step tutorials. In fact, we have used this feature to create an Interactive Quick Quiz for Eutectic Phase Diagrams (which will not be discussed further here). The image in Figure 3 was taken while signed in as the primary site user which thereby allows access to "analytics" from YouTube about the video. Finally, few of the comments of users include the following quotes:

"Good lecture....but the best is the voice of the girl speaking..."

"very helpful :)"

"You literally saved my life! Thank You, Thank You, Thank YOU!!!!! :D :D" 


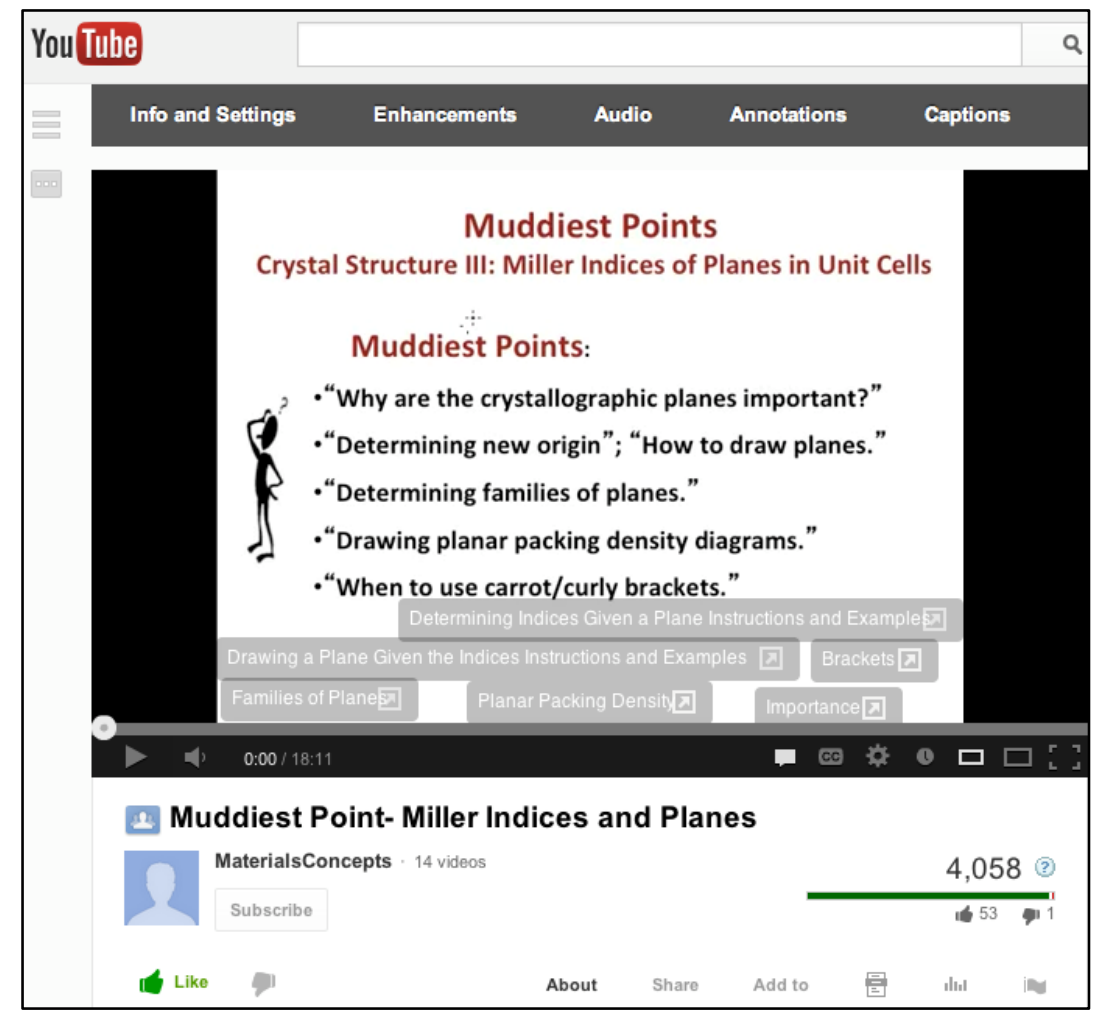

Figure 3. First slide of the Muddiest Point YouTube video for crystal plane Miller indices.

The next Selected Area Screenshot in Figure 4 shows the initial Analytics panel on YouTube for a video. This first shows that the total views for the site between Sept. 15, 2012 and Mar. 7, 2013 are 6,632 and that the video has been viewed for 36,649 minutes. The video also has 68 likes and 2 dislikes (both in Peru). It also has generated 29 subscribers with 29 comments, 4 shares, and 13 favorites. Gender usage is about $76.5 \%$ male and $23.5 \%$ female. The geography feature is shown visually, but it can produce lists that show that there have been viewers in 116 countries (about one half are United States) and in 49 states. Overall, the MaterialsConcepts YouTube channel has received over 25,000 hits in 130 countries, totaling over 116,000 minutes.

The analytics panel also contains more quantitative and geographical information. It includes information such as how many hits the video receives every day and how many unique viewers hit the video, as well as minutes viewed each day. The Analytics tool also shows the geographic distribution of hits for a given country, such as Botswana, or, for the United States, for a given state. So this makes it possible to see how many viewers spent how much time looking at a given video in Arizona or any other state. This will be discussed next. In Figure 5 is shown the analytics for the state of Arizona for the Muddiest Point Miller Indices video. It first shows a total of 208 views over 522 minutes. The views and minutes as a function of date are shown for the blue line on the left scale for views and for the mustard line on the right scale for minutes. It is no coincidence that the maximum number of minutes viewed were first on the day before the course final on Dec. 12, 2012 with 86 minutes and the second most minutes on Oct. 10th, 2012 which was the day before the first hourly exam. Students sought out the video to prepare for the exam - seven in October and six in December. In Test \#1 there was not a significant change in upper, median, and lower quartile scores compared to the trend line values over seven semesters. 


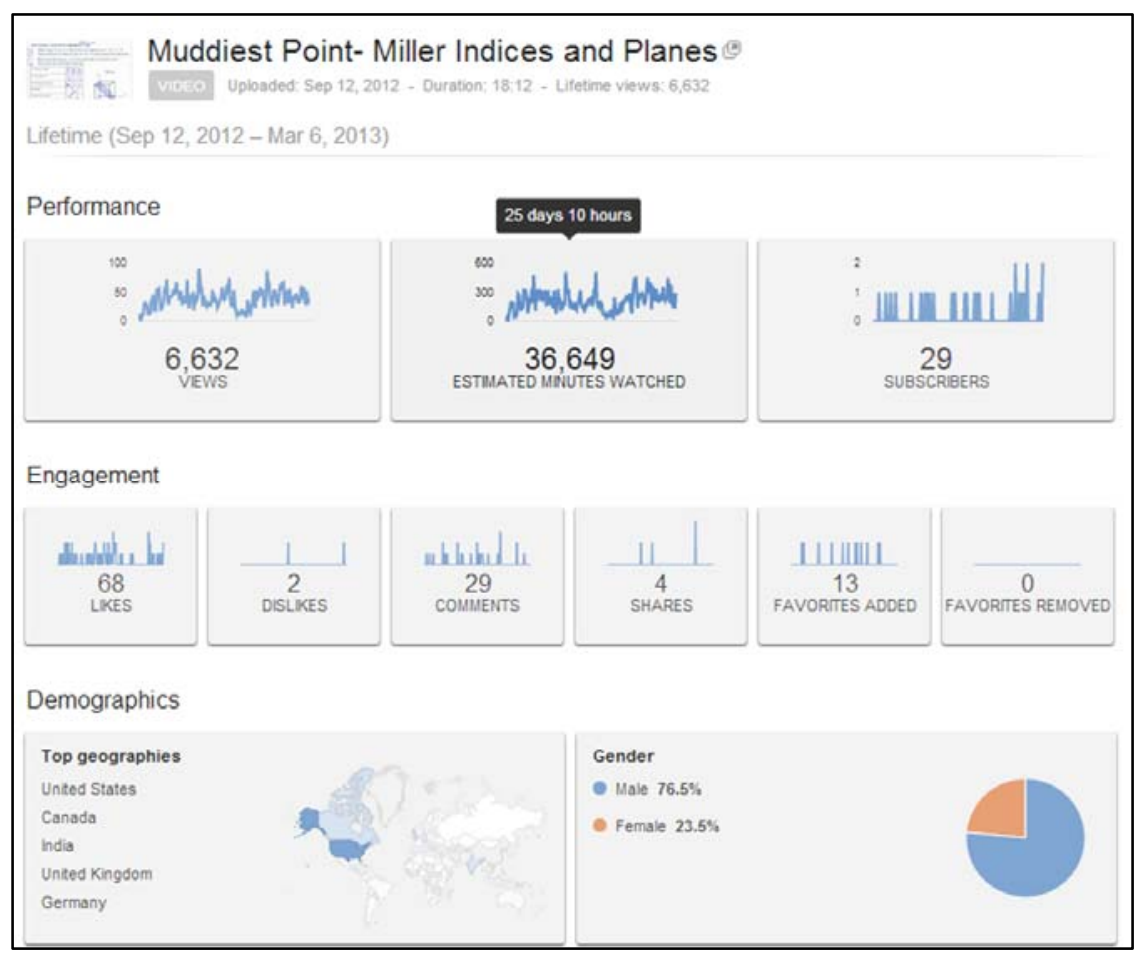

Figure 4. Analytics Panel for Muddiest Point YouTube video for Crystal Plan Miller Indices.

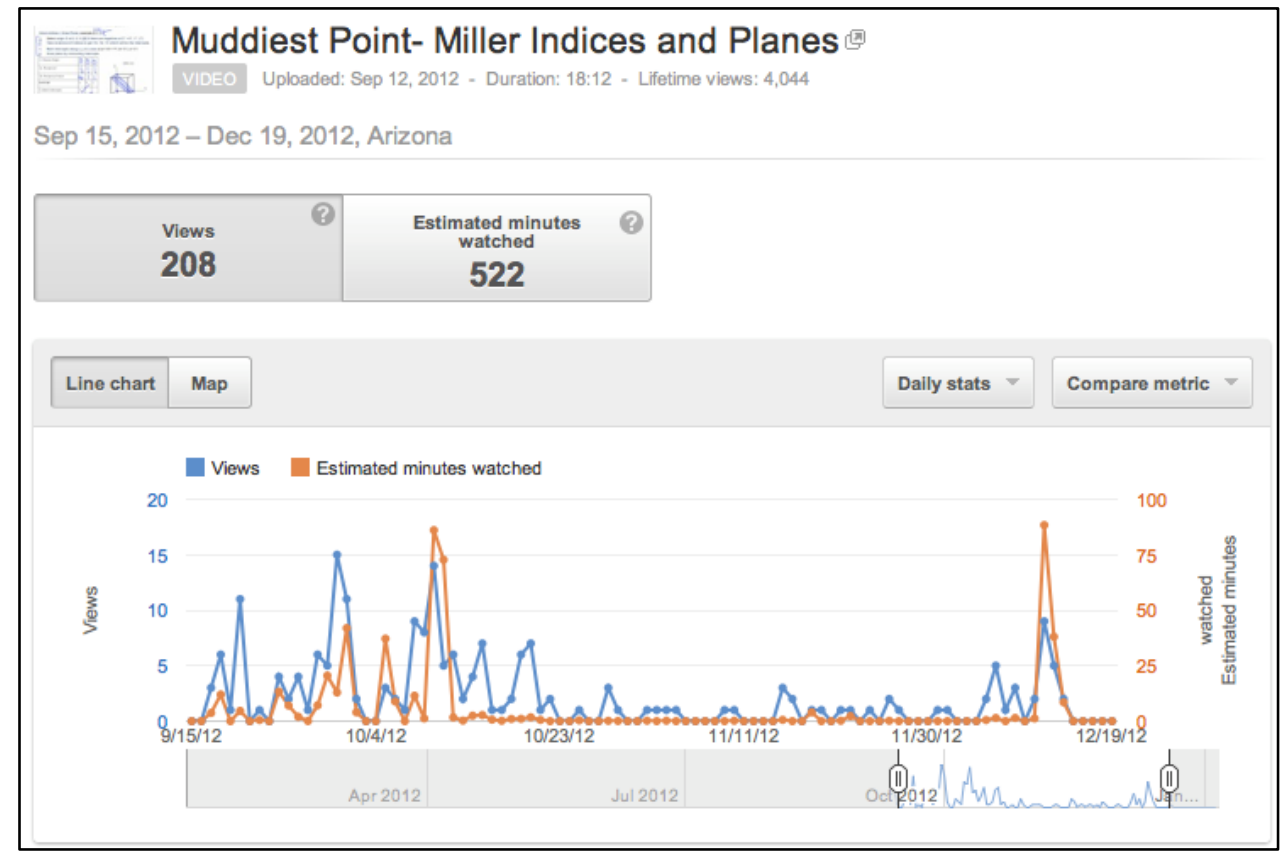

Figure 5. Analytics for Arizona of views and minutes versus date for the Miller Indices video.

While the previous YouTube video tutorial had little if any impact on student achievement, the Eutectic Phase Diagram Calculation (Figure 6) and Microstructure Muddiest Point Tutorial videos had a dramatic effect on scores on Test \#2 which was focused on phase diagram calculations and microstructures. We will discuss only the video usage for the Calculations video 
since the Microstructure video showed very similar features and trends. As can be seen below there is a significant spike on October 10, 2012 with 216 minutes and 30 unique viewers, which averages about 7 minutes per viewer. Tuesday, Oct 11, 2012 was the date of Test \#2. It should also be mentioned that there were a few viewers and a few minutes viewing on Thursday, Friday, and Sunday, as well as the big surge on Monday, but there were no viewers and no minutes on Saturday. There were also a few viewers and a few minutes on Dec. 10, 2012, the day before the final exam. The real surprise is in the impact that the video likely had on student achievement with significantly higher scores compared to trend lines for upper, median, and lower quartiles as shown in Figure 7. The following data compares scores from the Fall 2012 term to the trend lines created using previous semester scores. While the Test \#1 shows an average gain of +1 point and Test $\# 3$ shows an average gain of +2 points, the Test $\# 2$ shows an average gain of +8 points. The top quartile for Fall 2012 at 95\% was 6 points above the trend line, the median at 91\% was 7 points above the median trend line, and at $86 \%$ the lower quartile was 9 points higher than the trend line. A comparison of minutes watched in Arizona for all videos prior to course due dates is summarized below in Figure 8. These results could be anecdotal since no causal relationship was established, but this will be tested in the future. More specifically, we have developed a class resource site which allows for tracking of visitors to each source (for example, class notes, Muddiest Point videos, old test questions, a cyber-based vocabulary site called Quizlet, etc.). With this data, we can correlate use of resources to student performance (i.e., test and final exam scores).

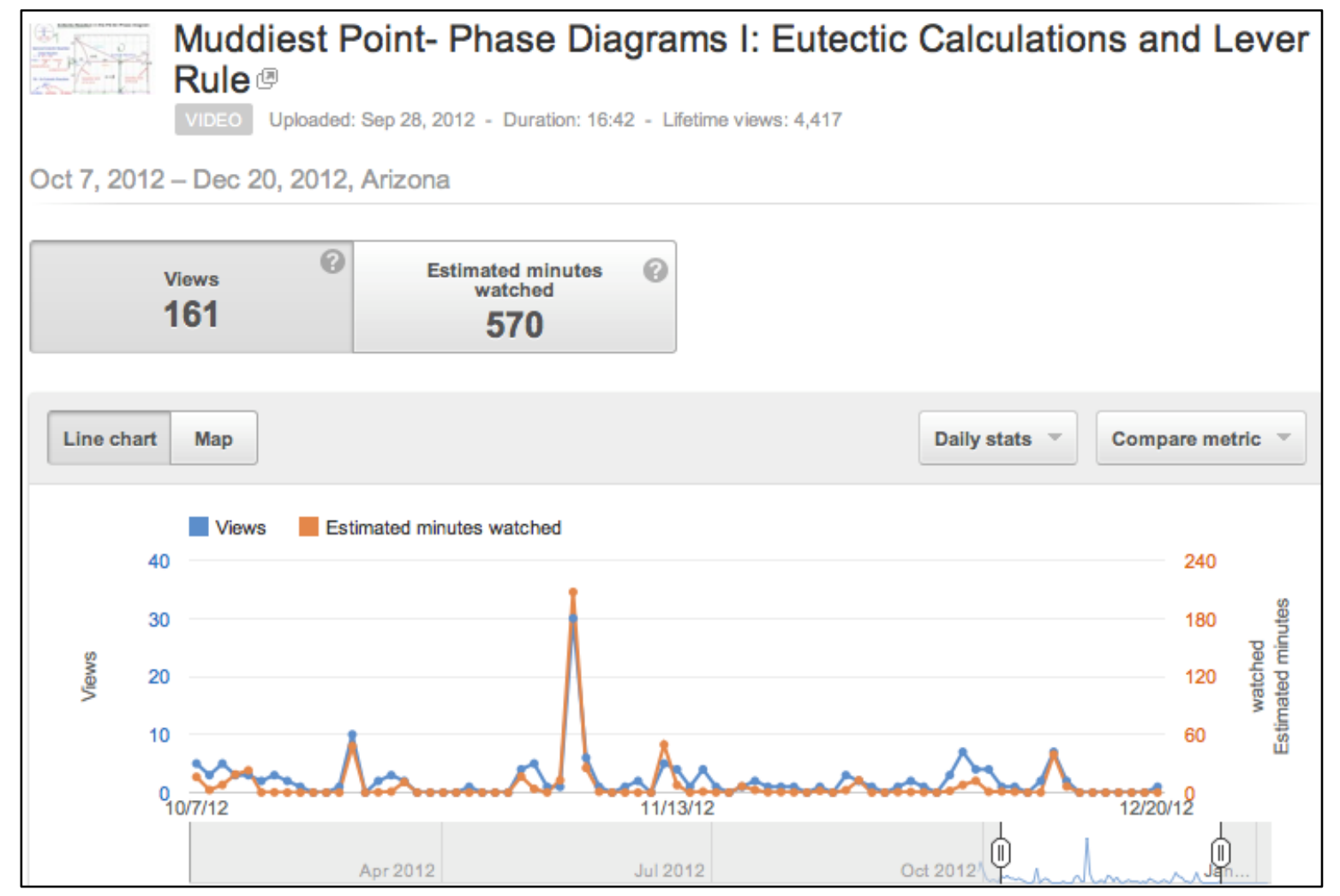

Figure 6. Analytics for Arizona of views and minutes and date for Eutectic Calculations video. 


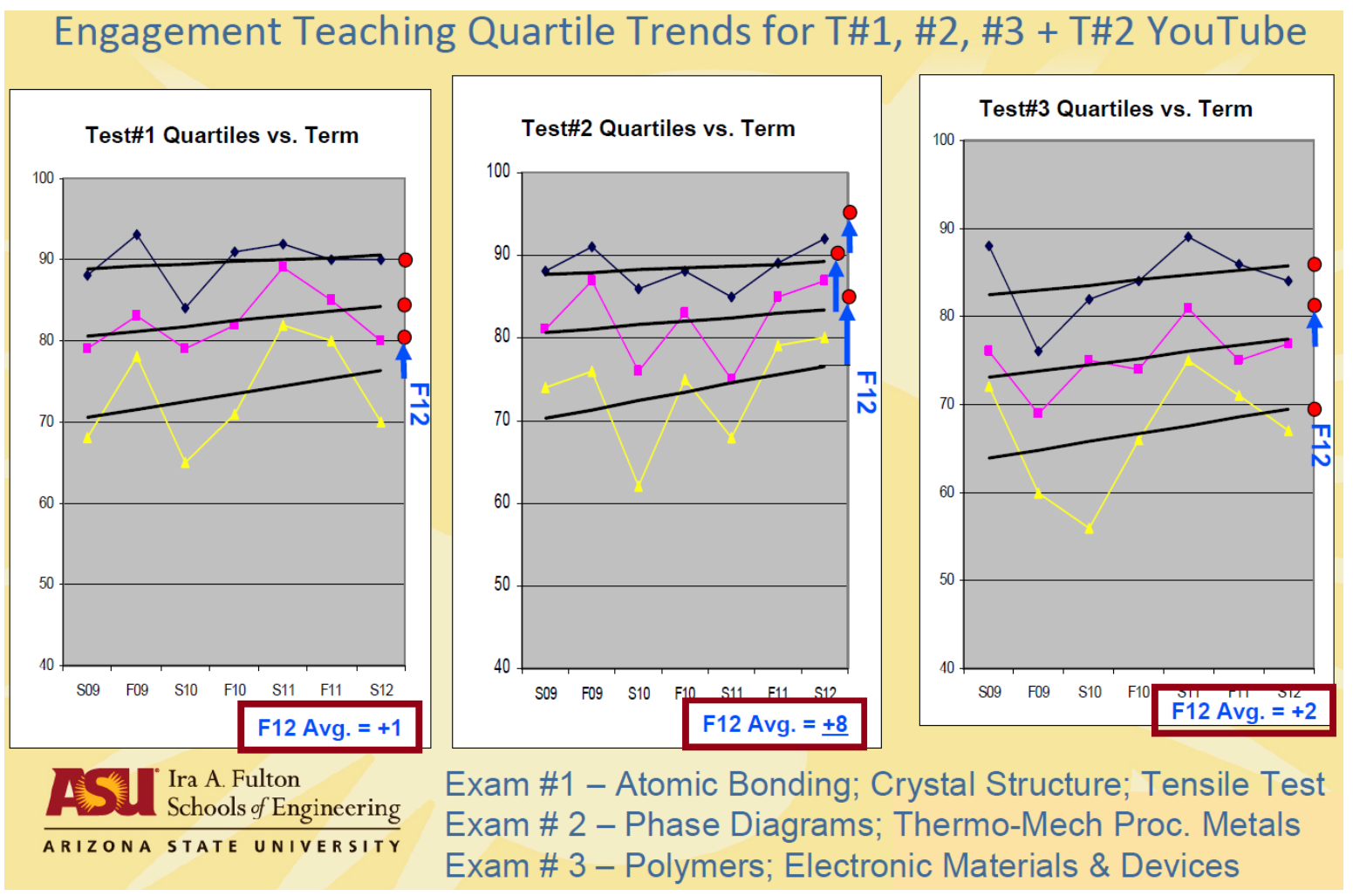

Figure 7. Trend lines for core materials classes for Tests \#1, \#2, and \#3 for the Fall 2012 semester. Average differences between F12 scores and the prior years trend lines were 1 point for $\mathrm{T} \# 18$ points for $\mathrm{T} \# 2$ and 2 points for $\mathrm{T} \# 3$.

\section{\% AZ Minutes Overlapping Course Activities}

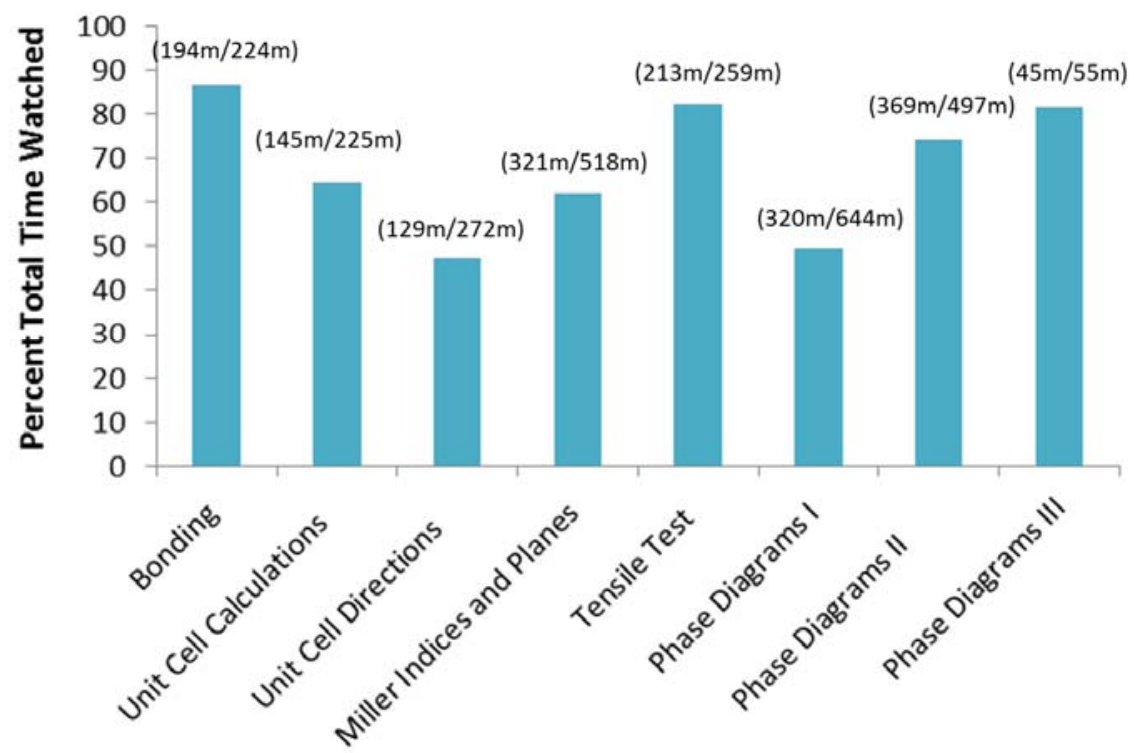

Figure 8. Percent of Minutes Watched in Arizona which overlap with Course Due Dates. 
Muddiest Points can also be used to generate Word Clouds as shown in Figure 9 for the topic of Atomic Bonding. The relative size of a word is related to its frequency of use in the Muddiest Points. From the Atomic Bonding Word Cloud it can be seen that the term van der Waals is largest. It is true that the majority of students entering introductory materials classes have never encountered the term van der Waals bonding since it is rarely used in an earlier prerequisite chemistry course. Sometimes chemistry teachers use the term London dispersion forces, which typically a few students may be familiar with. The point is that the word clouds are a useful tool to convey the fact to students or other instructors that there are issues with certain concepts. These issues need to be addressed in instruction and/or in future course design. Ideally, this should result in a reduction in the frequency of a term's use in the Muddiest Points class responses and a resulting decrease of the size of the term in the corresponding Word Cloud. This idea has not yet been explored, but will be in the future. The suggestion for using the Word Cloud for term frequency of Muddiest Points originated in the Koretsky Research Group at Oregon State University.

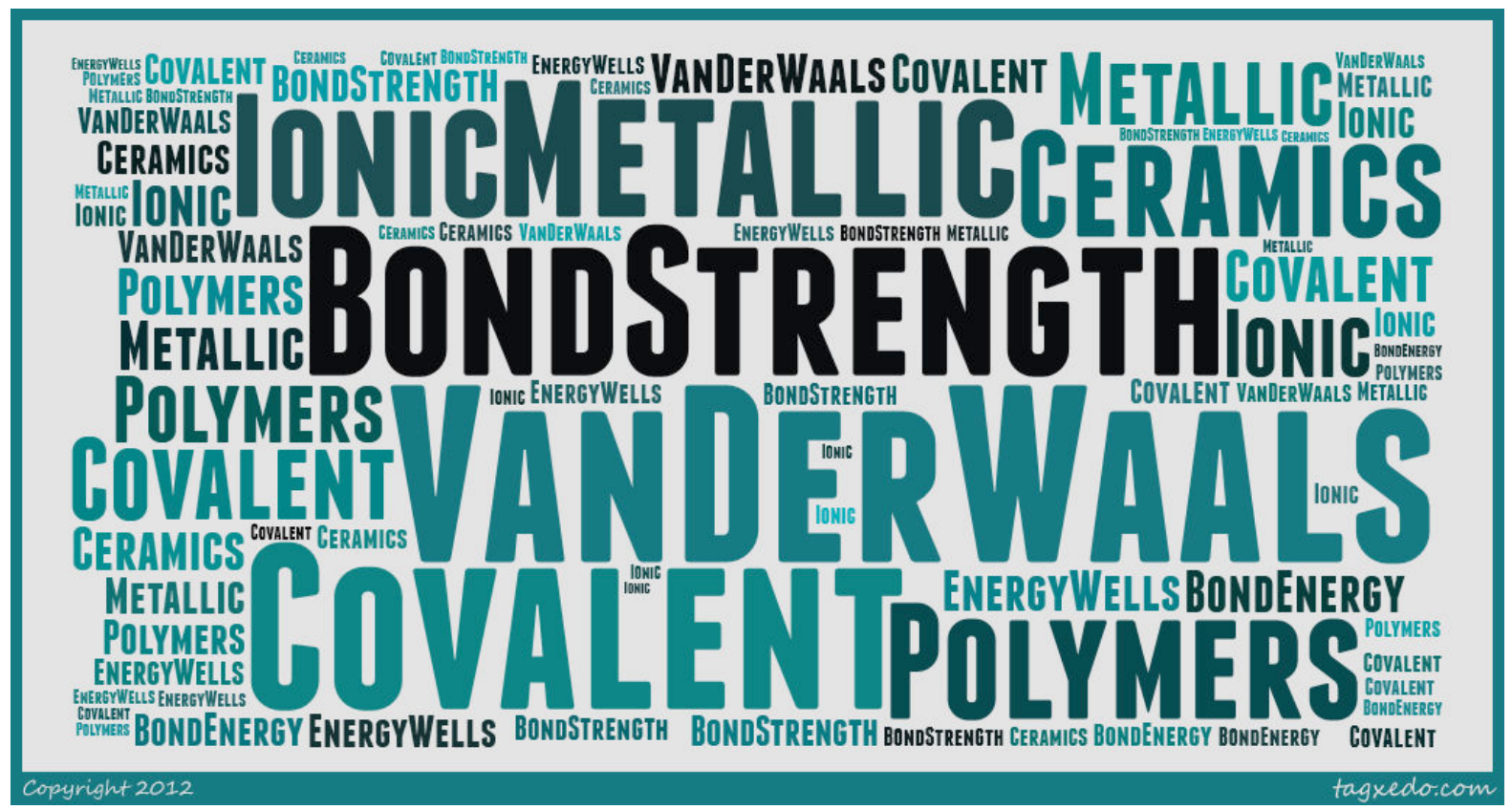

Figure 9. Atomic Bonding Word Cloud derived from frequency of word usage of terms highlighted by students in Atomic Bonding Muddiest Points.

\section{Impact of Muddiest Points on Student Attitude}

Motivation can be increased when students receiving frequent feedback by Muddiest Point activities so they recognize and identify with a course's relevance, significance, and possible value to their own future. When students are learning to bridge ideas from
Teaching Strategies to Support Learning - Agree or Strongly Agree

- 1) $82 \%$ - Team problem solving \& discussion helped

- 2) $93 \%$ - Hands-on activities supported learning

- 3) $93 \%$ - Muddiest Point next class discussion helped

- 4) 59\% - HW Preview Problem helped prepare for next class

- 5) $96 \%$ - UG teaching assistant working with teams

- 6) $93 \%$ - Muddiest-Point YouTube Tutorials

Figure 10. Impact on Student Attitude 
concrete contexts of a material with the familiar they also recognize their own relationship to these concrete contexts. When they reflect through Muddiest Points with situations related to these contexts, students can be better motivated to learn and continue in engineering. This is directly reflected in the affective portion of the previously cited exit survey for the Fall 2012 core materials class as shown in Figure 10. In particular, the results for the responses on the effect of teaching strategies on support of student learning had an average of $86 \%$ of students who found that the strategies supported or strongly supported their learning. The importance of Muddiest Points in the teaching strategies is highlighted by the fact that $93 \%$ of students supported or strongly supported Muddiest Point discussions as well as Muddiest Point YouTube videos. Motivation and self efficacy are promoted with the Muddiest Point activities and accounts in part for the $95 \%$ persistence rate of students in the Fall 2012 class.

\section{Collaborations}

Work reported in this paper represents part of an ongoing collaborative effort in a new TUES Type 2 project using engagement, assessment, and reflection tools developed in a successful CCLI Phase 1 project and adapting them to an interactive cyberenabled web environment. Using the tools in and out of class has potential to increase effectiveness and efficiency

of learning using frequent formative feedback to students. Innovations from

\begin{tabular}{|l|}
\hline PI Steve Krause - ASU \\
\hline co-PI Terry Alford, Candace Chan, Adam Carberry - ASU \\
\hline co-PI Cindy Waters - North Carolina A\&T \\
\hline co-PI Joe Stuart - Oregon Institute of Technology \\
\hline co-PI Brady Gibbons - Oregon State University \\
\hline co-PI Web Milo Koretsky- Oregon State University \\
\hline Advisory Board - Karl Smith, John Baglin, Kevin Trimble \\
\hline External Evaluator - Peggie Weeks; Internal - Dale Baker \\
\hline
\end{tabular}

Figure 11. JTF Participants and Roles

CCLI 1 are reflected in a new project title, Just-in-Time-Teaching with Interactive Frequent Formative Feedback (JiTTIFFF or JTF). In the JTF project there are collaborations between Arizona State University, a large public University, North Carolina A\&T, a medium size, historically black university; Oregon Institute of Technology, a medium size technology institute, and Oregon State University, a medium size, west coast university. Project participants, organizations, and roles are shown in Figure 8. Interactions between these institutions offer not a only a chance to test the effectiveness of the JTF approach in new settings with diverse populations, but to also test the ease of implementation of the interactive cyber-enabled platforms.

\section{Summary and Conclusions}

The research question for the work reported here was, "What is the effect on student learning and attitude of differing modes of feedback from students' Muddiest Point reflections?" This paper showed the theoretical framework for reflections and also showed how Muddiest Points were collected, recorded, and evaluated and used. One method was to restructure the notes from a given class and place the set on Blackboard so the new notes respond to student issues raised in Muddiest Points. A second method was with Class Warm-ups, which consist of a slide or two for discussion at the beginning of the next class which can help clarify confusing or difficult-tograsp concepts. Another method shown was to create Muddiest Point YouTube tutorial 
screencasts, such as the ones at www.youtube.com/user/MaterialsConcepts, which could be viewed by students to help resolve difficult concepts and also assist in solving homework problems. Preliminary results showed possible strong impact on student achievement in terms of significant gains with test results much higher than trend lines for upper, median and lower quartiles (over seven semesters) on content for which a Muddiest Point YouTube Tutorial screencast on Eutectic Phase Diagram Calculations had been created. A final supplemental approach was to incorporate Word Clouds in any of the feedback methods in which students' most significant issues can be highlighted with the Muddiest Point frequency of a given word as revealed by the size of a word in the Word Cloud. Overall, this paper showed the very positive potential impact of incorporating Muddiest Point strategies in teaching and learning for positive gains for student attitude, achievement and retention.

\section{Acknowledgement}

The authors acknowledge the support of this work from NSF Grants \#0836041 and \#1226325.

\section{Bibliography}

1. Pintrich, P. R., \& Schunk, D. H. (2002). Motivation in education: Theory, research, and applications. ( $2^{\text {nd }}$ edition). Upper Saddle River, NJ: Merrill, Prentice Hall.

2. Pajares, F. (1996). Self-efficacy beliefs in achievement settings. Rev. of Educational Res., 66, 543-578.

3. Malka, A., \& Covington, M. V. (2005). Perceiving school performance as instrumental to future goal attainment: Effects on graded performance. Contemporary Educational Psychology, 30, 60-80.

4. Wigfield, A. (1994). The role of children's achievement values in the self-regulation of their learning outcomes. In D. H. Schunk \& B. J. Zimmerman (Eds.), Self-regulation of learning and performance: Issues and educational applications (pp. 101-124). Mahwah, NJ: Erlbaum.

5. Miller, R.B., DeBacker, T., \& Greene, B. (1999). Perceived instrumentality and the incentive value of academic tasks. Journal of Instructional Psychology, 26, 250-260.

6. Wigfield, Allan L., and Jacquelynne S. Eccles. 2002. "Motivational beliefs, values, and goals." Annual Review of Psychology, 53, 109-32.

7. VanderStoep, S., Pintrich, P. R., \& Fagerlin, A. (1996). Disciplinary differences in self-regulated learning in college students. Contemporary Educational Psychology, 21, 345-362.

8. Simons, J., Dewitte, S., \& Lens, W. (2000). Wanting to have versus wanting to be: the influence of instrumentality on goal orientation. British Journal of Psychology, 91, 335-351.

9. Bandura, A. (1977). Social Learning Theory. Englewood Cliffs, NJ: Prentice-Hall.

10. Yasar, S. (2008). Discourse in Freshman Engineering Teams: The Relationship Between Verbal Persuasions, Self-Efficacy, and Achievement. (Unpublished dissertation). Arizona State Univ., Tempe.

11. Baumert, J., Evans, B. and Geiser, H., 1998. Technical problem solving among 10-year-old students as related to science achievement, out-of-school experience, domain-specific control beliefs, and attribution patterns. Journal of Research in Science Teaching 35 9, pp. 987-1013.

12. Grandy J (1994) Gender and ethnic differences among science and engineering majors: experiences, achievements, and expectations. Educational Testing Services, Princeton, NJ

13. LeBold, W. K. and Ward, S. K. [1998] "Engineering Retention: National and Institutional Perspectives," Proceedings, 1988 ASEE Annual Conference. ASEE, 1988. pp 843-851.

14. Zhang, Z. and RiCharde, R.S., [1998] "Prediction and Analysis of Freshman Retention" AIR 1998 Annual Forum Paper, Minneapolis, MN.

15. Zhang, G., Anderson, T., Ohland, M., Carter, R., \& Thorndyke, B. (2003). Identifying factors influencing engineering student graduation and retention: A longitudinal and cross-institutional study. American Society for Engineering Education Annual Conference, Nashville, Tennessee, USA. 
16. Betz, N. E., \& Hackett, G. (1981). The relationship of career-related self-efficacy expectation to perceived career options in college women and men. Journal of Counseling Psychology, 28, 399-410.

17. Bandura, A.1982.The psychology of chance encounters and life paths. American Psychologist37:747-55

18. Stamper, C. (1996). Fostering Reflective Thinking Through Computer Mediated Journaling. Unpublished doctoral dissertation. Tempe: Arizona State University.

19. Yinger, R. \& Clark, M. (1981). Reflective journal writing: Theory and practice. (Occasional Paper No. 50). East Lansing, M: Michigan State University. Institute for Research on Teaching.

20. Green, K.R., , Pinder-Grover, T., and Mirecki-Millunchick, J., Impact of Screencast Technology: Connecting the Perception of Usefulness and the Reality of Performance, Journal of Engineering Education, October 2012, Vol. 101, No. 4, pp. 717-737 (2012).

21. Traphagan, T., Kucsera, J., \& Kishi, K. (2010). Impact of class lecture webcasting on attendance and learning. Educational Technology Research and Development, 58 (1), 19-37.

22. Falconer, J.L., Nicodemus, G.D., deGrazia, J., and Medlin, J.W., Chemical Engineering Screencasts, Chemical Engineering Education 46, 58 (2012). 